
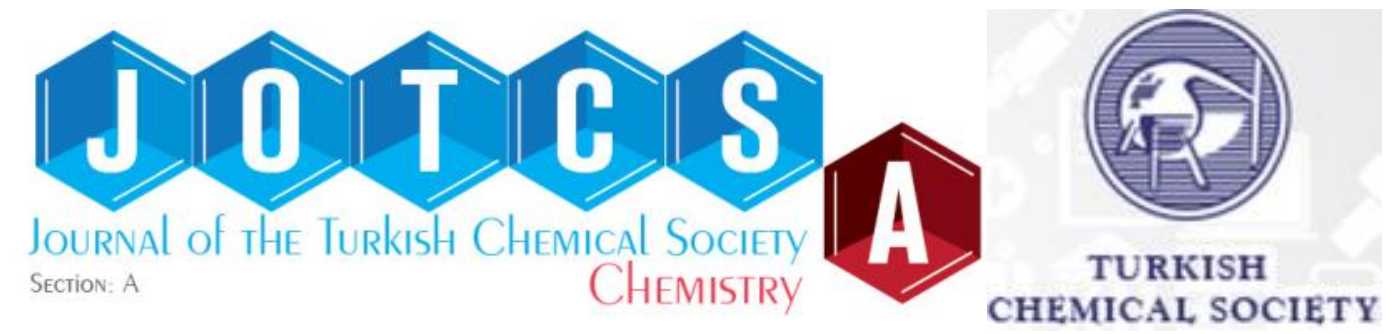

\title{
Optimization of Ultrasound-Assisted Extraction of Antioxidants from Apium graveolens $L$. Seeds using Response Surface Methodology
}

\author{
Şule Dinç Zor ${ }^{1 *}(\mathbb{D})$, Merve Bat ${ }^{1}(\mathbb{D})$, Ayşegül Peksel ${ }^{1}(\mathbb{D})$, Güzin Alpdoğan ${ }^{1}$ \\ ${ }^{1}$ Department of Chemistry, Faculty of Science and Arts, Yildiz Technical University, \\ 34210 Davutpasa-Istanbul, Turkey
}

\begin{abstract}
In this study, optimum conditions for ultrasound-assisted extraction (UAE) of antioxidants from Apium graveolens $L$. seeds were investigated by Response Surface Methodology (RSM). A Box-Behnken Design (BBD) was used to evaluate the effect of sonication time $(5,10,15 \mathrm{~min})$, ultrasound power $(60,120,180 \mathrm{~W})$, and the ratio of extraction solvent in terms of methanol $(0,50,100 \%)$ on antioxidant capacity. The optimal conditions of UAE for the parameters investigated were $11 \mathrm{~min}$ of sonication time, ultrasound power of $131 \mathrm{~W}$ and $100 \%$ methanol as an extraction solvent. Under these conditions, UAE of antioxidants from the seeds achieved a maximum of $95.08 \%$ in respect to 1,1-diphenyl-2-picryl hydrazyl (DPPH) radical scavenging activity. Additionally, the high value of the adjusted coefficient of determination $\left(R^{2}\right.$ adj $=0.9192$ ) and the non-significant difference between experimental and predicted values confirmed the validity of the quadratic polynomial model. Hence, UAE is a suitable, fast, economical and practical technique for the extraction of antioxidants from Apium graveolens $L$. seeds.
\end{abstract}

Keywords: Apium graveolens $L$. seed, ultrasound-assisted extraction, optimization, BoxBehnken Design, Response Surface Methodology (RSM).

Submitted: June 30, 2017. Accepted: September 07, 2017.

Cite this: Dinç Zor Ş, Bat M, Peksel A, Alpdoğan G. Optimization of Ultrasound-Assisted Extraction of Antioxidants from Apium graveolens L. Seeds using Response Surface Methodology. JOTCSA. 2017;4(3):915-30.

DOI: $10.18596 /$ jotcsa. 324848.

*Corresponding author. E-mail: sule dinc@yahoo.com. 
Dinc Zor, Bat, Peksel, Alpdogan, JOTCSA. 2017; 4(3): 915-930.

\section{INTRODUCTION}

In recent years, chemical methodologies have focused on the use of less toxic extractant phases and clean energies along with new techniques and materials in order to minimize human and environmental detriments. For instance, microextraction techniques have been developed instead of the more classical sample pretreatment-preconcentration techniques such as liquidliquid extraction and solid-phase extraction. Ultrasound that is one of the clean and efficient energy types has been commonly utilized for a good deal of sample preparation procedures (1). Various sample pretreatment steps such as digestion, dissolution, and extraction can easily be fulfilled thanks to its acoustic cavitation. This force can expedite the heat and mass transfer rate in order to disintegrate foods, sediments, soils or plant cell walls and allow the release of interested extractable substances. In terms of green chemistry, ultrasonic extraction has minimum solvent and energy consumption, effectiveness, and short operation time. It is also an easy-to-use and inexpensive method, so that it is employed in lots of studies in literature due to these many advantages (2-6).

Antioxidants neutralize reactive oxygen species including hydroxyl radicals, superoxide anions, nitric oxide, hydrogen peroxide, and so forth (7). Since they prevent cellular damage, aging, the creation and progress of cancer, and cardiac diseases, much interest has been shown in extracting natural antioxidant compounds from medicinal plants, herbal sources or vegetables. Apium graveolens $L$. which is widely known as celery contains flavonoids (apigenin, luteolin, and kaempferol), polyphenols ( $p$-coumaric acid, caffeic acid, and ferulic acid), terpenoids, alkaloids, tannins, essential oils, and glycosides as major components along with $\beta$-carotene, ascorbic acid, folic acid, minerals such as sodium, potassium and magnesium (8). Apium graveolens $L$. seeds have also antioxidant and antibacterial activity as well as diuretic, carminative, sedative, and antirheumatic effects and they have potential for therapeutic efficacy (Figure 1) (9).

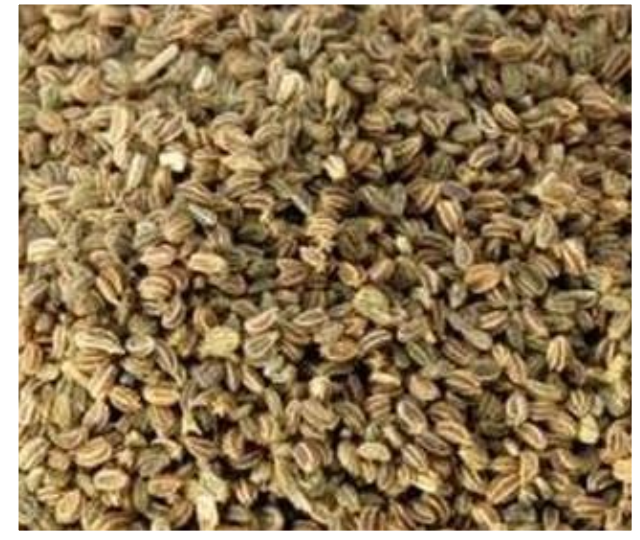

Figure 1: An image of Apium graveolens L. seeds.

Researchers have previously investigated antioxidant activity of Apium graveolens L. leaf, tuber, and seeds by using different extraction techniques containing Soxhlet (8-11), maceration, ultrasound-assisted, microwave-assisted, and supercritical carbon dioxide extraction (12). 
Dinc Zor, Bat, Peksel, Alpdogan, JOTCSA. 2017; 4(3): 915-930.

RESEARCH ARTICLE

Soxhlet extraction, which is a traditional extraction method is often time consuming and requires large amounts of organic solvents. Aydemir and Becerik (10) used this extraction technique which employed $150 \mathrm{~mL}$ of methanol and took for 4 hours in a shaker at room temperature. Maleki and coworkers (12) did not investigate optimum conditions for ultrasound-assisted extraction (UAE) of antioxidant activity from dried Apium graveolens $L$. in their studies. According to our literature survey, there is no study about optimization of UAE of antioxidants from Apium graveolens $L$. seeds. The key factors in UAE are type and ratio of extraction solvent, sonication time, ultrasound power, and so on, which need to be optimized. In this respect, He and coworkers optimized for microwave-assisted extraction conditions of total flavonoids, phenols and antioxidants from Apium graveolens $L$. leaves by experimental design (13).

Multivariate statistic techniques have been employed to optimize significant factors, making possible optimization of more than one factor simultaneously and so they give rise to different advantages including short operation-analysis time, cost-effective, reduced number of experiments, and consumption of solvents and materials needed (14). Response surface methodology (RSM) that can evaluate the effect of the factors and their interactions is a multivariate technique and is used to describe mathematical coherence of the experimental domain studied in the theoretical design through a response function (15). So far, RSM has been increasingly used to determine the optimum conditions of extraction techniques $(2,13,16,17)$, chromatographic $(18,19)$, and electroanalytical $(20,21)$ measurements.

This study has presented the use of RSM with Box-Behnken design (BBD) including three variables (sonication time, ratio of extraction solvent and ultrasound power) for the optimization of UAE of antioxidants from Apium graveolens $L$. seeds.

\section{EXPERIMENTAL SECTION}

\section{Instrumentation}

The antioxidant activity of Apium graveolens $L$. seed extracts was determined using a UV-Vis spectrophotometer (Mini UV 1240, Shimadzu, Tokyo, Japan). UAE process was performed using an Isolab ultrasonic bath (Wetheim, Germany) with the fixed-frequency of $40 \mathrm{kHz}$ and at three power settings of 60,120 and $180 \mathrm{~W}$. A vortex mixer, model IKA MS3 was obtained from Staufen, Germany. A Hettich centrifuge, model EBA20 from Tuttlingen, Germany was used for centrifuging. Both a domestic grinder and an Eppendorf automatic micro-pipettes with variable capacity were employed and obtained from Hamburg, Germany. 
Dinc Zor, Bat, Peksel, Alpdogan, JOTCSA. 2017; 4(3): 915-930.

RESEARCH ARTICLE

\section{Materials and Chemicals}

Apium graveolens $L$. seeds were purchased from a local herbalist in Istanbul, Turkey and were ground in a domestic grinder daily. 1,1-diphenyl-2-picryl-hydrazyl (DPPH) was purchased from Sigma (Sigma-Aldrich $\mathrm{GmbH}$, Sternheim, Germany). All other solvents were of analytical grade.

\section{Ultrasound-assisted Extraction (UAE)}

$0.50 \mathrm{~g}$ of the powdered seeds of Apium graveolens $L$. was placed in a $100 \mathrm{~mL}$ Erlenmeyer flask and extracted with $3.0 \mathrm{~mL}$ of the solvent investigated (methanol, ethanol or $50 \%$ methanol:ethanol) at different time intervals $(5,10,15 \mathrm{~min})$ and different power values $(60,120$ and $180 \mathrm{~W})$ of ultrasonic bath $(40 \mathrm{kHz})$ at room temperature $\left(25 \pm 1^{\circ} \mathrm{C}\right)$ with shaking. After the extraction process, the contents were centrifuged at $5000 \mathrm{rpm}$ for $15 \mathrm{~min}$. The supernatant was removed into a $50 \mathrm{~mL}$ beaker and evaporated under the fume hood. The residue was transferred into a $25 \mathrm{~mL}$ volumetric flask and diluted to its volume with absolute ethanol.

\section{Determination of Antioxidant Capacity}

The DPPH radical scavenging activity (DPPH SA, \%) is often used to evaluate the antioxidant capacity of compounds. The method of Brand-Williams et al. (22) was used for the determination of scavenging activity of DPPH radical. $0.75 \mathrm{~mL}$ of extract solution mixed with $1.50 \mathrm{~mL}$ of freshly prepared DPPH $(0.05 \mathrm{mM})$ in ethanol. The mixture was shaken vigorously and kept at room temperature for $30 \mathrm{~min}$. Then the absorbance was measured at $517 \mathrm{~nm}$ against a blank (without extract) in a UV-Vis spectrophotometer. The scavenging activity of DPPH radical (DPPH SA, \%) was calculated using the following formula:

$$
\text { DPPH SA }(\%)=\left[\frac{A_{\text {control }}-A_{\text {sample }}}{A_{\text {control }}}\right] \times 100
$$

Where $A_{\text {control }}$ and $A_{\text {sample }}$ are the absorbance of the control (DPPH solution without sample) and the absorbance of the test sample, respectively.

\section{Box-Behnken Experimental Design and Optimization by RSM}

The software Statgraphics Centurion XV (StatPoint, Inc., USA, 2005) was employed for experimental design, data analysis, and model building. The optimization step of the UAE was performed using a BBD with three levels, three factors incomplete factorial design. While the number of experiments required to investigate three factors at three levels should be $27\left(3^{3}\right)$, a BBD uses 15 experimental runs (23). Based on preliminary studies, sonication time $\left(X_{1}\right)$, ultrasound power $\left(\mathrm{X}_{2}\right)$ and ratio of extraction solvent $\left(\mathrm{X}_{3}\right.$, methanol:ethanol) were selected as factors with ranges of 5-15 $\mathrm{min}, 60-180 \mathrm{~W}$ and 0-100 \%, respectively. The response was measured as DPPH scaving activity (\%) as mentioned before. BBD is based on a second-order polynomial model, as follows (14): 
Dinc Zor, Bat, Peksel, Alpdogan, JOTCSA. 2017; 4(3): 915-930.

$$
\begin{gathered}
Y=\beta_{0}+\beta_{1} X_{1}+\beta_{2} X_{2}+\beta_{3} X_{3}+\beta_{12} X_{1} X_{2}+\beta_{13} X_{1} X_{3}+\beta_{23} X_{2} X_{3}+\beta_{11} X_{1}^{2} \\
+\beta_{22} X_{2}^{2}+\beta_{33} X_{3}^{2}
\end{gathered}
$$

Where $Y$ is the predicted response, $\beta_{0}$ is the constant, $\beta_{1}, \beta_{2}$ and $\beta_{3}$ are linear cofficients, $\beta_{12}$, $\beta_{13}$ and $\beta_{23}$ are interaction coefficients between the three invistigated factors, and $\beta_{11}, \beta_{22}$ and $\beta_{33}$ are quadratic coefficients. The analysis of variance (ANOVA) with $95 \%$ confidence level was carried out to confirm the significance of the estimated regression model.

Table 1: Coded and actual values of the factors selected for optimization of UAE.

\begin{tabular}{ccc}
\hline $\begin{array}{c}\text { Sonication time, } \mathbf{X}_{\mathbf{1}} \\
(\mathbf{m i n})\end{array}$ & Ultrasound power, $\mathbf{X}_{\mathbf{2}}(\mathbf{W})$ & Solvent Ratio, $\mathbf{X}_{\mathbf{3}}(\mathbf{\%})$ \\
\hline $5(-1)$ & $60(-1)$ & $0(-1)$ \\
$10(0)$ & $120(0)$ & $50(0)$ \\
$15(+1)$ & $180(+1)$ & $100(+1)$ \\
\hline
\end{tabular}

\section{RESULTS AND DISCUSSION}

\section{Modeling of Ultrasound-assisted Extraction (UAE) Process and Statistical Analysis}

In order to determine optimum conditions and investigate the effects of independent variables (factors) on UAE of antioxidants from the seeds, a Box-Behnken design was carried out and the experimental results obtained and predicted values were represented in Table 2 . After regression analysis was performed, the second-order polynomial model was developed between the response and three factors investigated. The best fitted model equation in terms of coded units was obtained as:

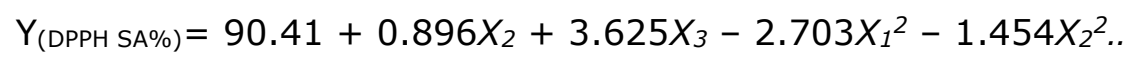

The adequacy and fitness of the model was tested by analysis of variance (ANOVA). The ANOVA results showing the significant factors for optimum UAE are presented in Table 3. The influence of critical factors and the model efficiency were evaluated according to Fisher's statistical analysis (F-value) and p-values obtained. The model F-value was determined as 18.70 , which indicates that the quadratic polynomial model is significant. The high determination coefficient $\left(R^{2}=0.9711\right)$ of the estimated model denotes that $97.11 \%$ of the variations in UAE process can be explained by the model. The adjusted $R^{2}\left(R^{2} a d j\right)$, which is more suitable for comparing models with different numbers of independent variables, is $91.92 \%$.

As seen Figure 2 and Table 3, while sonication time $\left(X_{1}\right)$ is not significant to the extraction procedure in the selected working range, ultrasound power $\left(X_{2}\right)$ and solvent ratio $\left(X_{3}\right)$ parameters were found as statistically significant. Quadratic contributions of sonication time $\left(\mathrm{X}_{1}{ }^{2}\right)$ and ultrasound power $\left(\mathrm{X}_{2}{ }^{2}\right)$ also influence the UAE significantly. Meanwhile, solvent ratio 
Dinc Zor, Bat, Peksel, Alpdogan, JOTCSA. 2017; 4(3): 915-930.

RESEARCH ARTICLE

$\left(\mathrm{X}_{3}\right)$ has a positive and the largest influence on UAE. It means the antioxidant activity increases with the increasing methanol ratio in the extraction solvent.

Table 2: Box-Behnken design matrix together with the experimental and predicted responses.

\begin{tabular}{|c|c|c|c|c|c|}
\hline \multirow[b]{2}{*}{ Run } & \multirow{2}{*}{$\underset{(\mathrm{min})}{\mathbf{X}_{1}}$} & \multirow{2}{*}{$\begin{array}{c}\mathbf{X}_{2} \\
(\mathbf{W})\end{array}$} & \multirow{2}{*}{$\begin{array}{c}X_{3} \\
(\%)\end{array}$} & \multicolumn{2}{|c|}{ DPPH SA (\%) } \\
\hline & & & & Experimental $^{a}$ & Predicted $^{\mathrm{b}}$ \\
\hline 1 & $5(-1)$ & $60(-1)$ & $50(0)$ & 85.00 & 84.70 \\
\hline 2 & $15(+1)$ & $60(-1)$ & $50(0)$ & 86.67 & 86.02 \\
\hline 3 & $5(-1)$ & $180(+1)$ & $50(0)$ & 85.56 & 86.21 \\
\hline 4 & $15(+1)$ & $180(+1)$ & $50(0)$ & 87.78 & 88.08 \\
\hline 5 & $5(-1)$ & $120(0)$ & $0(-1)$ & 85.02 & 84.33 \\
\hline 6 & $15(+1)$ & $120(0)$ & $0(-1)$ & 86.00 & 85.67 \\
\hline 7 & $5(-1)$ & $120(0)$ & $100(+1)$ & 91.00 & 91.33 \\
\hline 8 & $15(+1)$ & $120(0)$ & $100(+1)$ & 92.50 & 93.17 \\
\hline 9 & $10(0)$ & $60(-1)$ & $0(-1)$ & 84.00 & 84.98 \\
\hline 10 & $10(0)$ & $180(+1)$ & $0(-1)$ & 87.50 & 87.52 \\
\hline 11 & $10(0)$ & $60(-1)$ & $100(+1)$ & 93.00 & 92.98 \\
\hline 12 & $10(0)$ & $180(+1)$ & $100(+1)$ & 95.00 & 94.02 \\
\hline $13^{c}$ & $10(0)$ & $120(0)$ & $50(0)$ & 90.23 & 90.41 \\
\hline $14^{c}$ & $10(0)$ & $120(0)$ & $50(0)$ & 90.00 & 90.41 \\
\hline $15^{c}$ & $10(0)$ & $120(0)$ & $50(0)$ & 91.00 & 90.41 \\
\hline
\end{tabular}

a Experimental values of response.

b Predicted values of response by the second-order polynomial model.

c Central points used to determine the experimental error. 
Dinc Zor, Bat, Peksel, Alpdogan, JOTCSA. 2017; 4(3): 915-930.

Table 3: ANOVA results of optimization of UAE conditions.

\begin{tabular}{|c|c|c|c|c|c|c|}
\hline Source & $\begin{array}{l}\text { Sum of } \\
\text { Square }\end{array}$ & $\begin{array}{l}\text { Degree of } \\
\text { Freedom }\end{array}$ & $\begin{array}{l}\text { Mean of } \\
\text { Square }\end{array}$ & F-Value & P-Value & $\begin{array}{l}\text { Coefficient } \\
\text { Estimate }\end{array}$ \\
\hline Model & 155.63 & 9 & 17.29 & 18.70 & 0.0078 & 90.41 \\
\hline $\mathrm{X} 1$ & 5.10 & 1 & 5.10 & 5.52 & 0.0656 & 0.799 \\
\hline$x 2$ & 6.43 & 1 & 6.43 & 6.95 & 0.0462 & 0.896 \\
\hline$x 3$ & 105.12 & 1 & 105.12 & 113.68 & 0.0001 & 3.625 \\
\hline$x_{1}^{2}$ & 26.99 & 1 & 26.99 & 29.19 & 0.0029 & -2.703 \\
\hline$X_{1} X_{2}$ & 0.07 & 1 & 0.07 & 0.08 & 0.7864 & 0.137 \\
\hline$X_{1} X_{3}$ & 0.06 & 1 & 0.06 & 0.07 & 0.8053 & 0.125 \\
\hline$x_{2}^{2}$ & 7.80 & 1 & 7.80 & 8.44 & 0.0336 & -1.454 \\
\hline$X_{2} X_{3}$ & 0.56 & 1 & 0.56 & 0.61 & 0.4707 & -0.375 \\
\hline$x_{3}^{2}$ & 3.12 & 1 & 3.12 & 3.37 & 0.1258 & 0.919 \\
\hline Total error & 4.62 & 5 & 0.92 & & & \\
\hline Correct Total & 160.25 & 14 & & & & \\
\hline Model Summary & & & $\mathrm{R}^{2}$ & & $\mathrm{R}^{2}{ }^{a d j}$ & \\
\hline
\end{tabular}

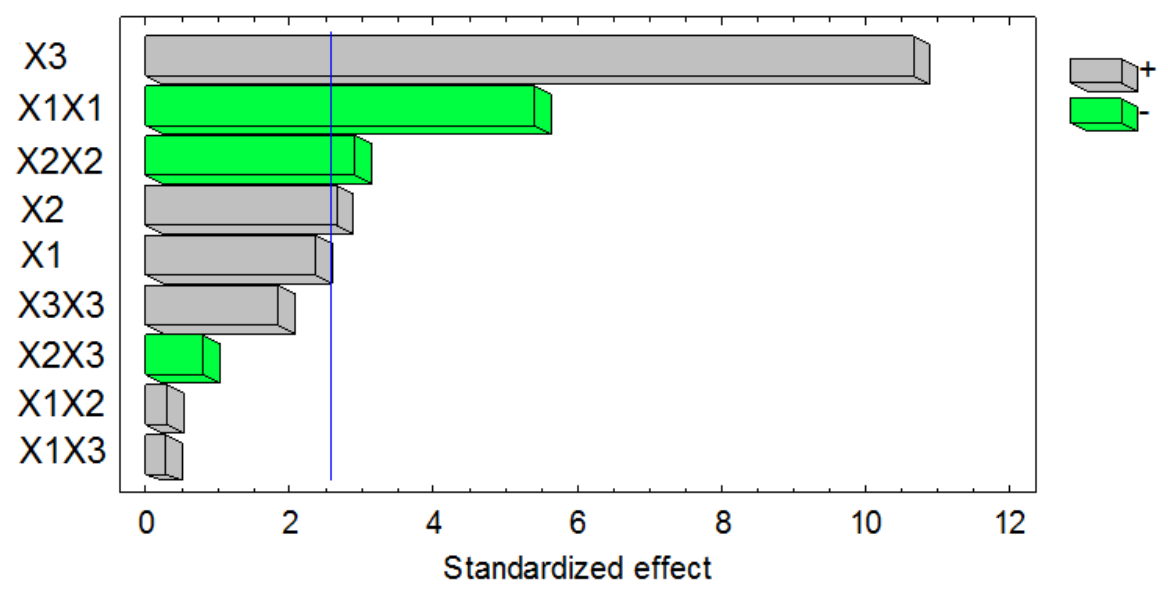

Figure 2. Pareto chart $(P=0.05)$ of standardized effects for BBD.

Additionally, it can be inferred that although sonication time $\left(X_{1}\right)$ and ultrasound power $\left(X_{2}\right)$ do not greatly influence the extraction procedure, better results are obtained for central or medium values of these parameters (Figure 3). Figure 4 also shows a good fitness between experimental and predicted values (this fact can also be observed in Table 2). 
Main Effects Plot for DPPH SA

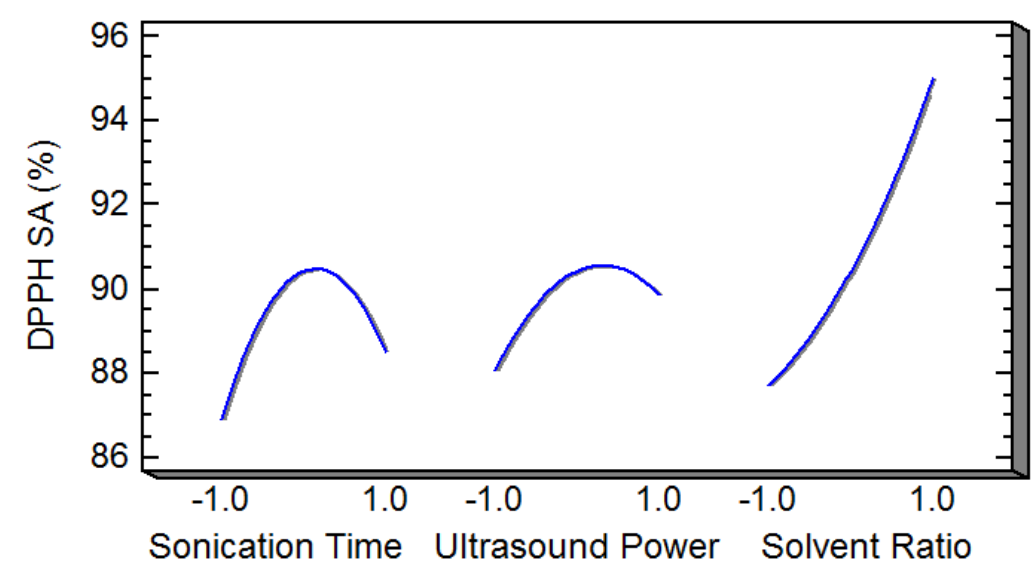

Figure 3: Main effect of each factor investigated on DPPH scavenging activity (\%).

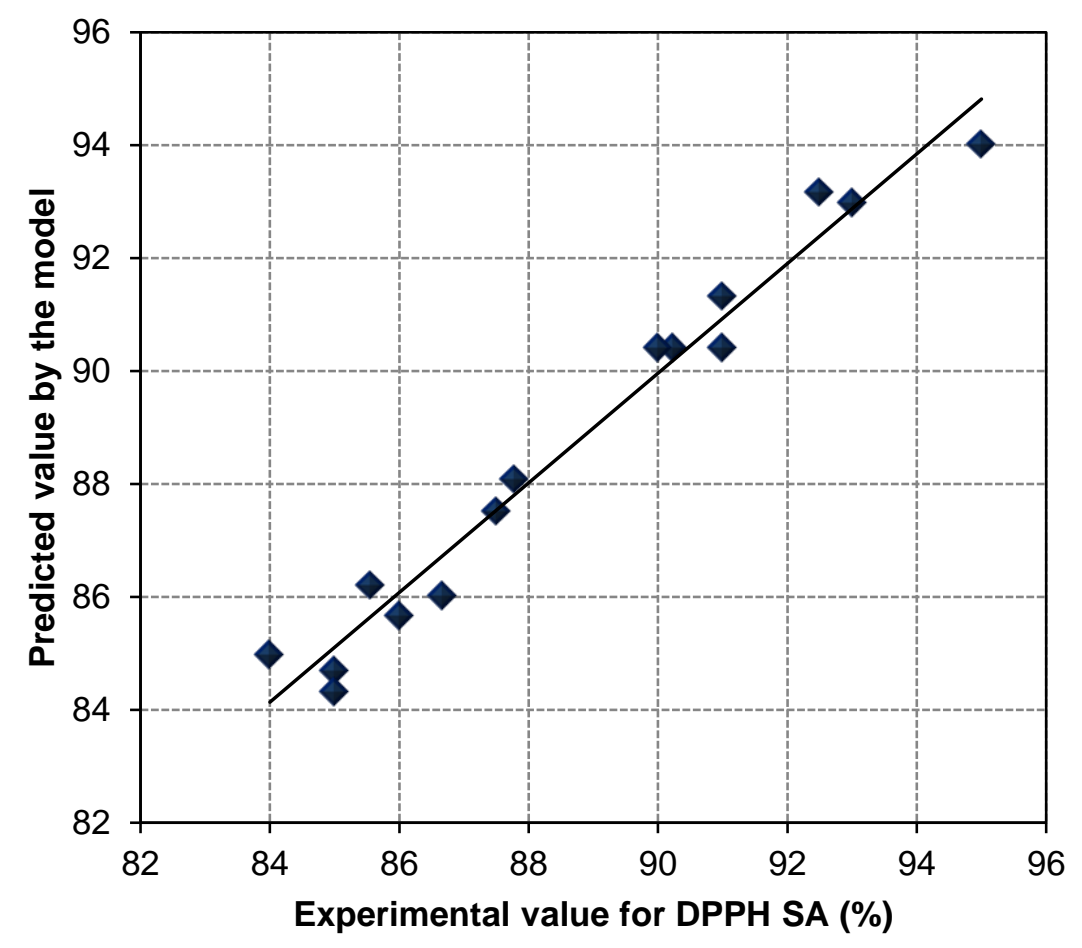

Figure 4: Correlation of experimental and predicted values for DPPH scavenging activity (\%).

\section{RSM Graphs and Optimum Conditions for UAE Process}

Three-dimensional (3D) response surface graphs were also plotted for the UAE procedure. The influence of sonication time and ultrasound power on DPPH scavenging activity was illustrated in Fig. 5a, with solvent ratio kept at its level +1 (100\% methanol). At the central values of these parameters, maximum responses were obtained for the UAE. Fig. $5 b$ reveals that an increase in the ratio of methanol in the extraction solvent resulted in higher antioxidant activity of the seeds and reached a maximum at $100 \%$ (predicted DPPH SA $95.0 \%$ ). In terms of methanol use, this result comforms to those of the studies conducted by Shanmugapriya and Ushadevi (9), Aydemir and Becerik (10) and Sameh et al. (11). Considering green chemistry, methanol is not a good option as an extraction solvent. But this study wants to indicate that the use of ultrasound for 
Dinc Zor, Bat, Peksel, Alpdogan, JOTCSA. 2017; 4(3): 915-930.

the extraction of antioxidants from Apium graveolens $L$. seeds is an efficient technique compared to conventional extraction techniques such as Soxhlet extraction and maceration which are required for much longer operation times and larger amounts of organic solvent. On the other hand, Maleki et al. found to be $98.71 \%$ the antioxidant activity of the tuber of celery by using water: ethanol (50:50) with the help of ultrasound without optimization (12). Sonication time of this study is $45 \mathrm{~min}$ in a ultrasonic bath having the power of $80 \mathrm{~W}$ at $37 \mathrm{kHz}$ frequency. For our study, the volume of methanol employed for each study is only $3.0 \mathrm{~mL}$ and the sonication time is $11 \mathrm{~min}$.

Fig. 5c also demonstrates that using intermediate power of ultrasound and only methanol as an extraction solvent lead to obtain better extraction efficiency.

According to overall results of optimization study, optimum conditions for the UAE of antioxidants from Apium graveolens $L$. seeds were obtained: sonication time: $11 \mathrm{~min}$; ultrasound power: 131 $\mathrm{W}$; and methanol ratio: $100 \%$.

It can be said that the UAE process developed is a fast and efficient method for extracting antioxidants from Apium graveolens $L$. seeds, thereby reducing the energy input. For the purpose of comparison in terms of operation time, extraction solvent type and ratio and so forth, Table 4 shows several applications of UAE of organic compounds from various matrix together with the optimal conditions of this study. These studies show that UAE has been used as an alternative to Soxhlet extraction and maceration. 
Dinc Zor, Bat, Peksel, Alpdogan, JOTCSA. 2017; 4(3): 915-930.

RESEARCH ARTICLE

Table 4: Summary of some reported studies on the UAE of natural compounds from different matrix.

\begin{tabular}{|c|c|c|c|c|}
\hline Analyte & Matrix & UAE Conditions & Analytical Technique & Ref \\
\hline Polyphenols & Olive tree leaves & $\begin{array}{l}50 \mathrm{kHz}, 60 \mathrm{~min} \text {, Ethanol } \\
(50 \%), 500 \mathrm{mg} \text { solid to } \\
10 \mathrm{~mL} \text { solvent ratio }\end{array}$ & $\begin{array}{l}\text { UV-Vis } \\
\text { Spectrophotometer }\end{array}$ & 2 \\
\hline $\begin{array}{l}\text { Antioxidants, } \\
\text { phenolic } \\
\text { compounds, } \\
\text { anthocyanins }\end{array}$ & $\begin{array}{l}\text { Red raspberry } \\
\text { puree }\end{array}$ & Water, $20 \mathrm{kHz}, 10 \mathrm{~min}$ & $\begin{array}{l}\text { Photochemiluminescence } \\
\text {, UV-Vis } \\
\text { Spectrophotometer }\end{array}$ & 3 \\
\hline $\begin{array}{l}\text { Catechins and } \\
\text { caffeine }\end{array}$ & Tea samples & $\begin{array}{l}10 \mathrm{~mL} \text { methanol }(8 / 2, \\
\mathrm{v} / \mathrm{v}) \text { or acetonitrile }(1: 1, \\
\mathrm{v} / \mathrm{v}), 10 \mathrm{~min}\end{array}$ & $\begin{array}{l}\text { HPLC-Diode Array } \\
\text { Dedector (DAD) }\end{array}$ & 4 \\
\hline Fatty acids & Caper seed oil & $\begin{array}{l}25 \mathrm{~mL} \text { of hexane, } \\
40{ }^{\circ} \mathrm{C}, 45 \mathrm{~min}, 50 \mathrm{kHz} \text {, } \\
550 \mathrm{~W}\end{array}$ & $\begin{array}{l}\text { Gas chromatography- } \\
\text { MS }\end{array}$ & 5 \\
\hline Polysaccharides & $\begin{array}{l}\text { Longan fruit } \\
\text { pericap }\end{array}$ & $\begin{array}{l}120 \mathrm{~W}, 22 \mathrm{~min}, 60^{\circ} \mathrm{C} \text { or } \\
241 \mathrm{~W}, 18 \mathrm{~min}, 51^{\circ} \mathrm{C} \text {, in } \\
\text { water at } 40 \mathrm{kHz} \text {. }\end{array}$ & $\begin{array}{l}\text { UV-Vis } \\
\text { Spectrophotometer }\end{array}$ & 6 \\
\hline Polyphenols & Orange peel & $\begin{array}{l}25 \mathrm{kHz}, 150 \mathrm{~W}, 40{ }^{\circ} \mathrm{C}, \\
\text { Ethanol: water }(4: 1, \mathrm{v} / \mathrm{v}) \text {, } \\
30 \mathrm{~min}\end{array}$ & $\begin{array}{l}\text { HPLC, UV-Vis } \\
\text { Spectrophotometer }\end{array}$ & 16 \\
\hline $\begin{array}{l}\text { Phenolic } \\
\text { compounds, } \\
\text { antioxidants, } \\
\text { anthocyanins }\end{array}$ & Grape & $\begin{array}{l}10 \mathrm{~L}, 50 \% \text { Ethanol, } \\
24 \mathrm{~min}\end{array}$ & $\begin{array}{l}\text { UV-Vis } \\
\text { Spectrophotometer }\end{array}$ & 24 \\
\hline $\begin{array}{l}\text { Antioxidants, } \\
\text { flavonoids }\end{array}$ & Citrus peel & $\begin{array}{l}\text { Methanol, } \\
40^{\circ} \mathrm{C}, 30^{\prime} \mathrm{min}\end{array}$ & $\begin{array}{l}\text { HPLC-DAD-mass } \\
\text { spectrometry (MS) }\end{array}$ & 25 \\
\hline $\begin{array}{l}\text { Phenolic and } \\
\text { silymarin } \\
\text { compounds }\end{array}$ & Milk thistle seeds & $\begin{array}{l}\text { Methanol, different time } \\
\text { intervals }(30,60,90 \text {, } \\
120 \text {, and } 150 \mathrm{~min})\end{array}$ & $\begin{array}{l}\text { UV-Vis } \\
\text { Spectrophotometer, } \\
\text { HPLC }\end{array}$ & 26 \\
\hline Flavonoids & $\begin{array}{l}\text { Adinandra nitida } \\
\text { leaves }\end{array}$ & $\begin{array}{l}45 \mathrm{kHz}, \\
\text { Ethanol }(63.84 \%) \\
30.25 \mathrm{~min}\end{array}$ & $\begin{array}{l}\text { UV-Vis } \\
\text { Spectrophotometer }\end{array}$ & 27 \\
\hline $\begin{array}{l}\text { Phenolic and } \\
\text { flavonol } \\
\text { compounds, } \\
\text { antioxidants }\end{array}$ & Grape pomace & $\begin{array}{l}\text { Water as an extraction } \\
\text { solvent, } 40 \mathrm{kHz}, 150 \mathrm{~W} / \mathrm{L} \text {, } \\
25 \mathrm{~min}\end{array}$ & $\begin{array}{l}\text { UV-Vis } \\
\text { Spectrophotometer }\end{array}$ & 28 \\
\hline Anthocyanins & Red raspberries & $\begin{array}{l}1.5 \mathrm{M} \mathrm{HCl} \text { : Ethanol }(85 \% \\
\mathrm{v} / \mathrm{v} \%)(15: 85, \mathrm{v} / \mathrm{v}), 3.3 \\
\mathrm{~min}\end{array}$ & HPLC-MS & 29 \\
\hline Anthocyanins & Haskap berries & $\begin{array}{l}40 \mathrm{kHz}, 100 \mathrm{~W}, 80 \% \\
\text { Ethanol (contain } 0.5 \% \\
\text { formic acid), } 35^{\circ} \mathrm{C}, 20 \\
\text { min }\end{array}$ & $\begin{array}{l}\text { UV-Vis } \\
\text { Spectrophotometer, } \\
\text { HPLC }\end{array}$ & 30 \\
\hline Antioxidants & $\begin{array}{l}\text { Apium graveolens } \\
\text { L. seeds }\end{array}$ & $\begin{array}{l}40 \mathrm{kHz}, 131 \mathrm{~W} \text {, in } \\
\text { methanol, } 11 \mathrm{~min}\end{array}$ & $\begin{array}{l}\text { UV-Vis } \\
\text { Spectrophotometer }\end{array}$ & $\begin{array}{l}\text { This } \\
\text { work }\end{array}$ \\
\hline
\end{tabular}



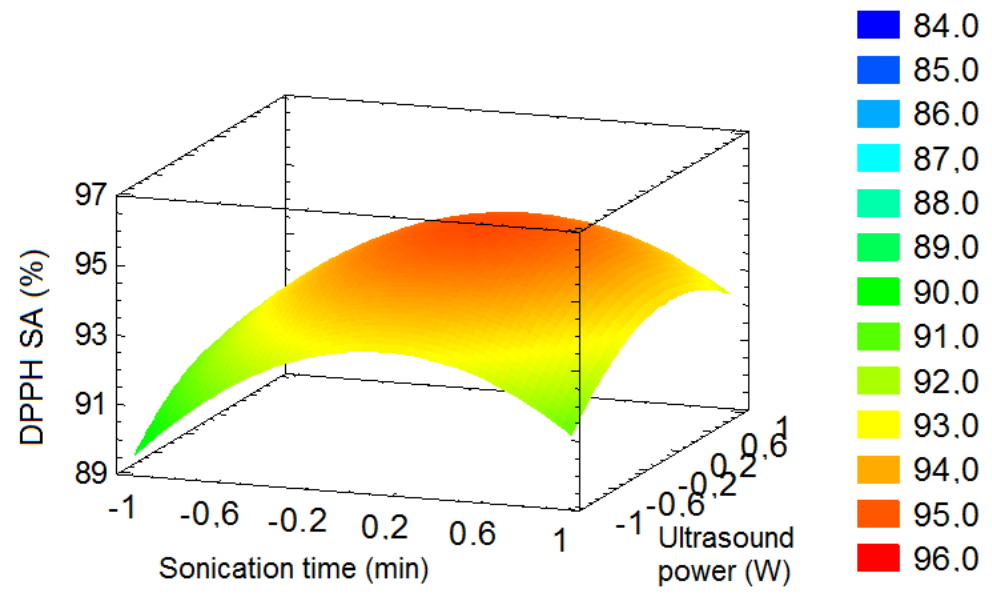

(a)

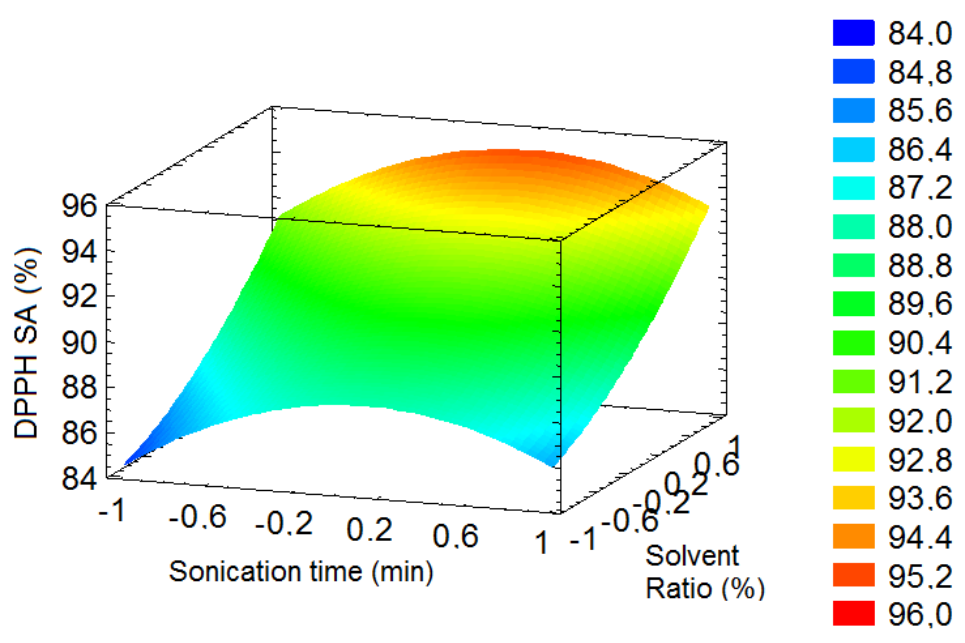

(b)

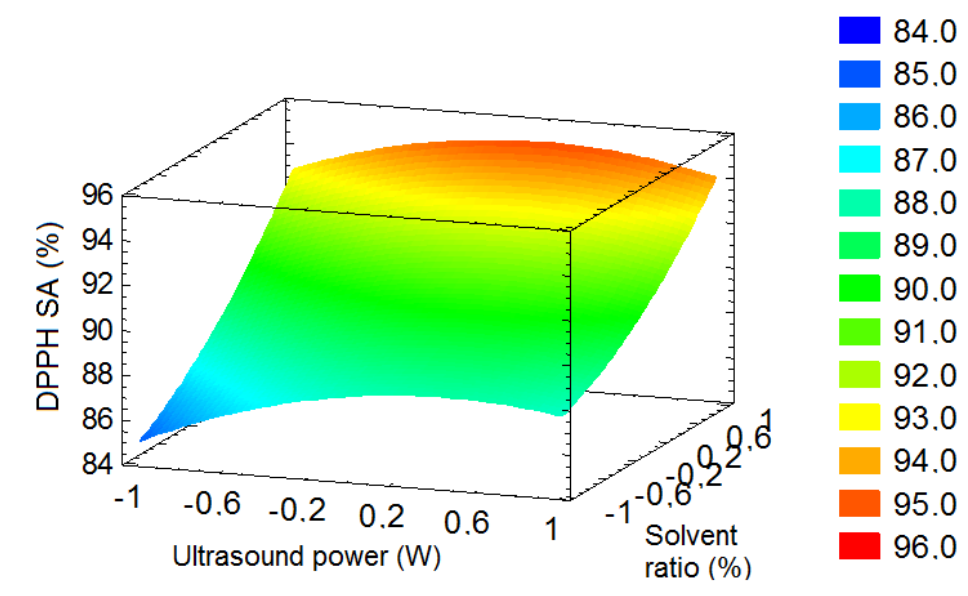

(c)

Figure 5: Response surface plots for the antioxidant capacity of the extracts as a function of (a) sonication time to ultrasound power (solvent ratio = methanol $100 \%$ ); (b) sonication time to solvent ratio (ultrasound power $=131 \mathrm{~W}$ ); (c) ultrasound power to solvent ratio (sonication time $=11 \mathrm{~min})$. 
Dinc Zor, Bat, Peksel, Alpdogan, JOTCSA. 2017; 4(3): 915-930.

RESEARCH ARTICLE

\section{CONCLUSIONS}

The ultrasound-assisted extraction of antioxidants from Apium graveolens $L$. seeds has been developed and demonstrated to be effective, fast, low-cost, and practical. Conditions of the UAE process were successfully optimized by response surface methodology using Box-Behnken design. Furthermore, the effects of main factors and possible interactions between factors were investigated. As expected, the results revealed that antioxidant activity of Apium graveolens $L$. seeds was influenced most significantly by the ratio of extraction solvent in the selected working range. The mathematical model obtained by RSM also has a high determination coefficient ( $\mathrm{R}^{2}$ $=0.9711, \mathrm{R}^{2}$ adj $\left.=0.9192\right)$ and shows a good agreement between the predicted and corresponding experimental results. Consequently, antioxidants from Apium graveolens $L$. seeds can be extracted at a high rate and efficiency by using ultrasound-assisted extraction.

\section{COMPLIANCE WITH ETHICAL STANDARDS}

The authors declare that there is not an unethical situation.

\section{CONFLICT OF INTEREST}

The authors declare that they have no conflict of interest.

\section{REFERENCES}

1. Bendicho C, De La Calle I, Pena F, Costas M, Cabaleiro N, Lavilla I. Ultrasound-assisted pretreatment of solid samples in the context of green analytical chemistry. Trends in Analytical Chemistry. 2012; 31:50-60. DOI: 10.1016/j.trac.2011.06.018.

2. Şahin S, Şamlı R. Optimization of olive leaf extract obtained by ultrasound-assisted extraction with response surface methodology. Ultrasonics Sonochemistry. 2013; 20:595-602. DOI: 10.1016/j.ultsonch.2012.07.029

3. Golmohamadi A, Möller G, Powers J, Nindo C. Effect of ultrasound frequency on antioxidant activity, total phenolic and anthocyanin content of red raspberry puree. Ultrasonics Sonochemistry. 2013;20:1316-1323. DOI: 10.1016/j.ultsonch.2013.01.020

4. Gu X, Cai J, Zhang Z, Su Q. Dynamic ultrasound-assisted extraction of catechins and caffeine in some tea samples. Annali di Chimica. 2007;97:321-330. DOI: 10.1002/adic.200790018.

5. Ara KM, Karami M, Raofie F. Application of response surface methodology for the optimization of supercritical carbon dioxide extraction and ultrasound-assisted extraction of Capparis spinosa 
Dinc Zor, Bat, Peksel, Alpdogan, JOTCSA. 2017; 4(3): 915-930.

seed oil. The Journal of Supercritical Fluids. 2014;85:173- 182. DOI:10.1016/j.supflu.2013.10.016.

6. Yang B, Zhao M, Shi J, Yang N, Jiang Y. Effect of ultrasonic treatment on the recovery and DPPH radical scavenging activity of polysaccharides from longan fruit pericarp. Food Chemistry. 2008;106: 85-690. DOI: 10.1016/j.foodchem.2007.06.031.

7. Shahidi F, Ambigaipalan P. Phenolics and polyphenolics in foods, beverages and spices: Antioxidant activity and health effects - A review. Journal of Functional Foods. 2015; 18:820897. DOI:10.1016/j.jff.2015.06.018.

8. Yao Y, Sang W, Zhou M, Ren G. Phenolic composition and antioxidant activities of 11 celery cultivars. Journal of Food Science. 2010;75(1):9-13. DOI: 10.1111/j.1750-3841.2009.01392.x.

9. Shanmugapriya $R$, Ushadevi $T$. In vitro antibacterial and antioxidant activities of Apium graveolens L. seed extracts. International Journal of Drug Development and Research. 2014;6 (3):165-170.

10. Aydemir T, Becerik S. Phenolic content and antioxidant activity of different extracts from Ocimum basilicum, Apium graveolens and Lepidium sativum seeds. Journal of Food Biochemistry. 2011;35:62-79. DOI: 10.1111/j.1745-4514.2010.00366.x.

11. Sameh B, Ibtissem B, Mahmoud A, Boukef K, Boughattas NA. Antioxidant activity of Apium graveolens extracts. Journal of Biologically Active Products from Nature. 2011; 1(5-6):340-343. DOI: $10.1080 / 22311866.2011 .10719102$.

12. Maleki M, Ariaii P, Fallah H. Effects of celery extracts on the oxidative stability of canola oil under thermal condition. Journal of Food Processing and Preservation. 2016;40: 531-540. DOI: $10.1111 /$ jfpp. 12632.

13. He $\mathrm{Q}$, Li $\mathrm{Y}$, Zhang $\mathrm{P}$, Zhang $\mathrm{A}$, Wu $\mathrm{H}$. Optimisation of microwave-assisted extraction of flavonoids and phenolics from celery (Apium graveolens L.) leaves by response surface methodology. Czech Journal of Food Science. 2016;34(4). DOI: 10.17221/266/2015-CJF.

14. Montgomery DC. Design and analysis of experiments. Wiley, New York, 2004.

15. Bezerra MA, Santelli RE, Oliveira EP, Villar LS, Escaleira L A. Response surface methodology (RSM) as a tool for optimization in analytical chemistry. Talanta. 2008; 76(5): 965-977. DOI: 10.1016/j.talanta.2008.05.019. 
Dinc Zor, Bat, Peksel, Alpdogan, JOTCSA. 2017; 4(3): 915-930.

16. Khan MK, Abert-Vian M, Fabiano-Tixier AS, Dangles O, Chemat F. Ultrasound-assisted extraction of polyphenols (flavanone glycosides) from orange (Citrus sinensis L.) peel. Food Chemistry. 2010;119:851-858. DOI:10.1016/j.foodchem.2009.08.046.

17. Alberti A, Zielinski AAF, Zardo DM, Demiate IM, Nogueira A, Mafra L. Optimisation of the extraction of phenolic compounds from apples using response surface methodology. Food chemistry. 2014;149: 151-158. DOI: 10.1016/j.foodchem.2013.10.086.

18. Dinç Zor Ş, Aş̧ı B, Aksu Dönmez Ö, Yıldırım Küçükkaraca D. Simultaneous determination of potassium sorbate, sodium benzoate, quinoline yellow and sunset yellow in lemonades and lemon sauces by HPLC using experimental design. Journal of Chromatographic Science. 2016; 1-6. DOI: $10.1093 /$ chromsci/bmw027.

19. Dinç Zor Ş, Aksu Dönmez Ö, Aşçı B, Yarkadaş G. A novel RP-HPLC method for the simultaneous analysis of some active ingredients in cough-cold syrup formulation. Current Pharmaceutical Analysis. 2017; 13(3):304-313. DOI: 10.2174/1573412912666160517123419.

20. Trindade JM, Martiniano LC, Gonçalves VR, Souza AG, Marques AL, Baugis GL, Marques EP. Anodic stripping voltammetry coupled with design of experiments for simultaneous determination of $\mathrm{Zn}+2, \mathrm{Cu}+2, \mathrm{~Pb}+2$, and $\mathrm{Cd}+2$ in gasoline. Fuel. 2012; 91(1):26-32. DOI:10.1016/j.fuel.2011.06.015.

21. Bisetty K, Sabela MI, Khulu S, Xhakaza M, Ramsarup L. Multivariate optimization of voltammetric parameters for the determination of total polyphenolic content in wine samples using an immobilized biosensor. International Journal of Electrochemical Science. $2011 ; 6: 3631$ 3643.

22. Brand-Williams $W$, Cuvelier ME, Berset $C$. Use of a free radical method to evaluate antioxidant activity. Lebensmittel-Wissenschaft \& Technologie.1995;28:25-30. DOI: 10.1016/S0023-6438(95)80008-5.

23. Ferreira SC, Bruns RE, Ferreira HS, Matos GD, David JM, Brandao G C, Dos Santos WNL. Box-Behnken design: an alternative for the optimization of analytical methods. Analytica Chimica Acta. 2007;597(2):179-186. DOI:10.1016/j.aca.2007.07.011.

24. Ghafoor K, Choi YH, Jeon JY, Jo IH. Optimization of ultrasound-assisted extraction of phenolic compounds, antioxidants, and anthocyanins from grape (Vitis vinifera) seeds. Journal of Agricultural and Food Chemistry. 2009; 57(11):4988-4994. DOI:10.1021/jf9001439. 
Dinc Zor, Bat, Peksel, Alpdogan, JOTCSA. 2017; 4(3): 915-930.

25. Londoño-Londoño J, de Lima VR, Lara O, Gil A, Pasa TBC, Arango GJ, Pineda JRR. Clean recovery of antioxidant flavonoids from citrus peel: optimizing an aqueous ultrasound-assisted extraction method. Food Chemistry. 2010;119(1):81-87. DOI: $10.1016 /$ j.foodchem.2009.05.075.

26. Çağdaş E, Kumcuoğlu S, Güventürk S, Tavman Ş. Ultrasound-assisted extraction of silymarin components from milk thistle seeds (Silybum marianum L.) Gıda. 2011; 36 (6): $311-318$.

27. Liu B, Ma Y, Liu Y, Yang Z, Zhang L. Ultrasonic-assisted extraction and antioxidant activity of flavonoids from Adinandra nitida leaves. Tropical Journal of Pharmaceutical Research. 2013; 12(6):1045-1051. DOI: 10.4314/tjpr.v12i6.27.

28. Gonzalez-Centeno MR, Knoerzer K, Sabarez H, Simal S, Rossello C, Femenia A. Effect of acoustic frequency and power density on the aqueous ultrasonic-assisted extraction of grape pomace (Vitis vinifera L.) - A response surface approach. Ultrasonics Sonochemistry. 2014;21:2176-2184. DOI: 10.1016/j.ultsonch.2014.01.021.

29. Chen F, Sun Y, Zhao G, Liao X, Hu X, Wu J, Wang Z. Optimization of ultrasound-assisted extraction of anthocyanins in red raspberries and identification of anthocyanins in extract using high-performance liquid chromatography-mass spectrometry. Ultrasonics Sonochemistry. 2007;14(6):767-778. DOI: 10.1016/j.ultsonch.2006.12.011.

30. Celli GB, Ghanem A, Brooks MSL. Optimization of ultrasound-assisted extraction of anthocyanins from haskap berries (Lonicera caerulea L.) using response surface methodology. Ultrasonics Sonochemistry. 2015;27:449-455. DOI: 10.1016/j.ultsonch.2015.06.014. 
